\title{
Improving the Effectiveness of Automatic Pure Tone Audiometer with Audiogram and Patient Diagnosis
}

\author{
Aulia Rahmawati, I Dewa Gede Hari Wisana, Endang Dian Setioningsih, Sari Luthfiyah, Bedjo Utomo \\ Department of Medical Electronics Engineering Technology Politeknik Kesehatan Kementerian Kesehatan Surabaya \\ Jl. Pucang Jajar Timur No. 10, Surabaya (60282), Indonesia \\ E-mail: liarahmawatiaul@yahoo.co.id,Hariwisana@yahoo.com,diancholik@gmail.com, sariluthfiyah@yahoo.co.id
}

\begin{tabular}{|c|c|}
\hline Article Info & Abstract \\
\hline $\begin{array}{l}\text { History Articles: } \\
\text { Received May 15, } 2020 \\
\text { Revised Nov 14, } 2020 \\
\text { Accepted Nov 25, } 2020\end{array}$ & $\begin{array}{l}\text { Conventional Audiometer testing using manual mode takes quite a long time for one patient, and the } \\
\text { audiologist must accompany until the test is complete. The purpose of this research is to design a pure } \\
\text { tone audiometer with an automatic mode using Arduino microcontrollers. Contributions from this } \\
\text { research is a system of automatic running to improve health services. The Hughson Westlake method } \\
\text { is used for automatic mode. The method is prepared in the Arduino software and uses the CD4066 }\end{array}$ \\
\hline $\begin{array}{l}\text { Keywords: } \\
\text { Automatic } \\
\text { Audiometer } \\
\text { Pure Tone } \\
\text { Audiograms } \\
\text { Frequency } \\
\text { XR2206 }\end{array}$ & $\begin{array}{l}\text { digital switch to regulate the frequency and intensity given to the patient. As for the frequency } \\
\text { generator using XR2206, the raised frequencies are } 250,500,1000,2000,4000,8000 \mathrm{~Hz} \text {. Then the } \\
\text { patient will press the interrupt button if listening to sound, and the result will be displayed to the } \\
\text { Audiogram on Android. Patient diagnostic results can be seen when testing the entire frequency has } \\
\text { been completed. At frequency } 250 \mathrm{~Hz} \text { obtained error value } 0.13 \text {, at frequency } 500 \mathrm{~Hz} \text { obtained error } \\
\text { value } 4.37 \text {, at frequency } 1000 \mathrm{~Hz} \text { obtained error value } 39.5 \text {, at the frequency of } 2000 \mathrm{~Hz} \text { obtained error } \\
\text { value } 24.67 \text {, at the frequency of } 4000 \mathrm{~Hz} \text { obtained error value } 67.33 \text {. And at the frequency of } 8000 \mathrm{~Hz} \\
\text { obtained error value } 32.33 \text {. The results of this study showed that the highest error was } 3.95 \% \text { at } \\
1000 \mathrm{~Hz} \text { frequency and the smallest error was } 0.05 \% \text { at } 250 \mathrm{~Hz} \text { frequency. The results of this study can } \\
\text { be implemented in conventional audiometer system to accelerate testing time to improve service and } \\
\text { facilitate audiologist during hearing testing. }\end{array}$ \\
\hline
\end{tabular}

The corresponding author:

I Dewa Gede Hari Wisana

Department of Medical Electronics Engineering Technology

Politeknik Kesehatan Kementerian Kesehatan Surabaya

J1. Pucang Jajar Timur No. 10, Surabaya (60282), Indonesia

E-mail: Hariwisana@yahoo.com
This jobopen access articles and licensed under $\underline{\text { Creative }}$ Commons Attribution-Non-Commercial 4.0 License International,

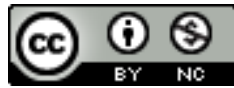

\section{INTRODUCTION}

Humans are wrapped around five senses that are instrumental in living life, one of which is the sense of hearing. The senses of human hearing play an important role in undergoing social interactions with the environment. The human hearing threshold can hear the sound at a frequency of $20 \mathrm{~Hz}-20,000 \mathrm{~Hz}$ [1]. However, human voice is about 8000 $\mathrm{Hz}$ or less. In general, the human word is expressed frequency 200 to $8000 \mathrm{~Hz}$ [2]. According to the World Health Organization (WHO) The article 2019 states that more than 5\% of the world's population or 466 million people experience hearing impairment (432 million adults and 34 million children). It is estimated that in 2050 more than 900 million people or one in every ten people will experience hearing loss [3]. Hearing loss can be caused by factors such as taking too much medication, ear infections, too often in a noisy place [4],[5]. Middle ear diseases, such as chronic otitis media, otosclerosis, and cholesteanoma, often cause conductive hearing loss, which affects millions of people around the world [6]. The main factor is aging so that parents are more likely to experience hearing loss than young people [7]. Hearing loss can be a hindrance in communicating. In addition, hearing loss can impede social involvement, causing a person with hearing impairment to feel depressed, isolate themselves, and exit social activities [7], [8]. A simple cervical test can help to find out early hearing disorders such as tuning fork tests and whisper sound tests, but the tests are less standardized and do not provide objective data [8]. A pure tone audiometer test is required to address the problem because it is very useful for determining the auditory threshold for the degree characterization, type and configuration of hearing loss [9],[10] and simple in hearing testing[11]. However, a conventional audiometer may take a long time to perform a hearing test.

Many researchers have created and developed a pure tone audiometer for early detection of decreased hearing ability, for example, in 2012 Isler and Yigit have created a portable Audiometer with 2 modes i.e. manual and automatic, this 
audiometer can be connected to the computer to see the test results and test results on the audiometers are read using the LED indicator but the tool still uses microcontrollers PIC16F877 [12]. In addition, Rani's 2016 Portable Audiometer was used to continuously monitor remote hearing [4]. Rani's audiometer test results will be delivered to the health unit. This audiometer's weakness does not display the patient's diagnostic results only with the frequency and intensity of the patient. Then in the same year Isler has developed an Audiometer tool with 3 test modes with an audiogram display on a 4.3 inch TFT display [13]. The downside of Isler's proprietary audiometer is that the output volume on the display does not equal the output volume from the source. In 2018 Ik-So and Myung-Jin had created an audiometer with an automated system [14]. The time it takes to perform a hearing test is less than 5 minutes so it can save a lot of time, but the hearing test performed only 3 levels of volume is- $3 \mathrm{~dB},-10 \mathrm{~dB}$ and $-30 \mathrm{~dB}$. Then Marwa et al. In 2018 created a pure tone audiometer application with an audiogram with MATLAB software [15]. This app is designed with sound cards to get pure tones. The downside of this audiometer system does not run automatically and does not display the results of patient diagnostics.

Based on the weaknesses and limitations that earlier researchers have mentioned, among others 1). Using microcontrollers PIC16F877, 2). Does not display the patient diagnose results, 3 ). The output volume on the screen is not the same as the actual output volume, 4). The measured intensity is only 3 levels, namely- $3 \mathrm{~dB},-10 \mathrm{~dB}$ and $-30 \mathrm{~dB}, 5)$. The tool system is still manual and does not display the patient diagnose results. The benefits of automatic audiometry are standardized testing procedures and protocols, improved diagnostic accuracy by reducing clinical variability and efficient listening test data storage [16]. Hence the purpose of this researcher is to design a pure tone audiometer with an automated system using an Arduino equipped an audiogram graph on Android and is expected to diagnose up to severe deafness. The audiometer is expected to improve hearing loss testing services at the clinic/hospital, which can save time for hearing loss testing and can facilitate audiologist during hearing testing..

This article is composed of: Chapter I Introduction, Chapter II Material \& Method, Chapter III Result, Chapter IV Discussion, and Chapter V Conclusion.

\section{MATERIALS AND METHODS}

\section{A. experimental setup}

This study uses the DSO138 Digital Oscilloscope measuring instrument. Retrieving data is done sequentially from low to high frequencies. 6 sets of data measurement at each frequency.

\section{1) Materials and Tools}

This study used the XR-2206CP Monolithic Function Generator (F0921, EXAR Corporation, Fremont-United States), CD4066BE CMOS Quad Bilateral Switch (22AMS13 E7, Texas Instruments, Texas-United States), and Amplifier LM386N-1 Module (National Semiconductor, China).
Components used as microcontroller sensors Arduino (Mega Pro Mini, Arduino.cc, Italy), Solid State Relay (G3MB-202P, OMRON, Japan), Bluetooth HC-05 (BC417, E-Gizmo Mechatronix Central, Philippines) and MIT App Inventor as display. Then to headphones using the ATH-AVC200 of Audio Technica in Japan.

\section{2) Trial}

In this study, researchers measured the output of the XR2206 oscillator series using the DSO138 Digital Oscilloscope from the frequency of $250 \mathrm{~Hz}, 500 \mathrm{~Hz}, 1000 \mathrm{~Hz}$, $2000 \mathrm{~Hz}, 4000 \mathrm{~Hz}$ and $8000 \mathrm{~Hz}$. Measurements performed 6 sets then the results were searched mean value and compared to the actual value to get the error value.

\section{B. Block diagram and flowchart}

When the power switch is ON, then all circuits get the voltage supply, as shown in Fig.1.

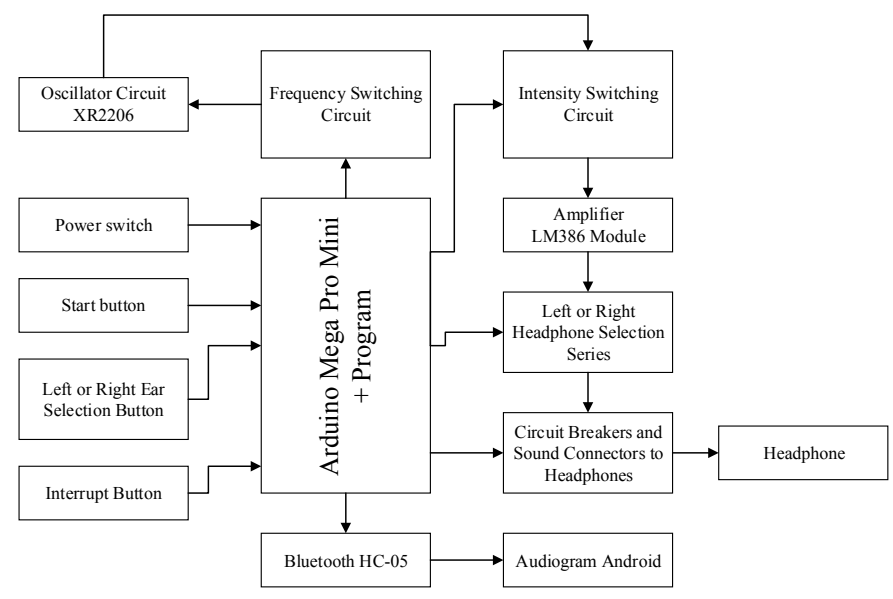

Fig. 1. A block diagram of Automatic Pure Tone Audiometer

In Fig. 1 The frequency switching range is used to alter the frequency of the audiometer triggered by the Arduino and the output goes into the circuit oscillator. A series of oscillators here using IC XR-2206 can produce sinus signals. Then the sine signals as inputs of the circuit switching intensity. The switching intensity range is a series of voltage divider that can regulate the amplitude of the sinus signal. This series is also triggered from the Arduino to enable the digital switch. The output will be strengthened by the amplifier circuit. Then forwarded to the right or left headphone selection set. The series is triggered by the Arduino, when high-value it will be connected to the circuit breaker and the sound connector to the headphones. Circuit breaker and sound connector to the headphones is also triggered by the Arduino, when high-value it will connect to the headphones. Before performing an audiometer check, the audiologist needs to select a right or left ear check using the right or left ear selection button. When the Start button is pressed then the check starts and the system 
will run automatically. The interrupt button is pressed when the patient listens for sound, and the stored data will be sent by Bluetooth and in the Audiogram display on Android.

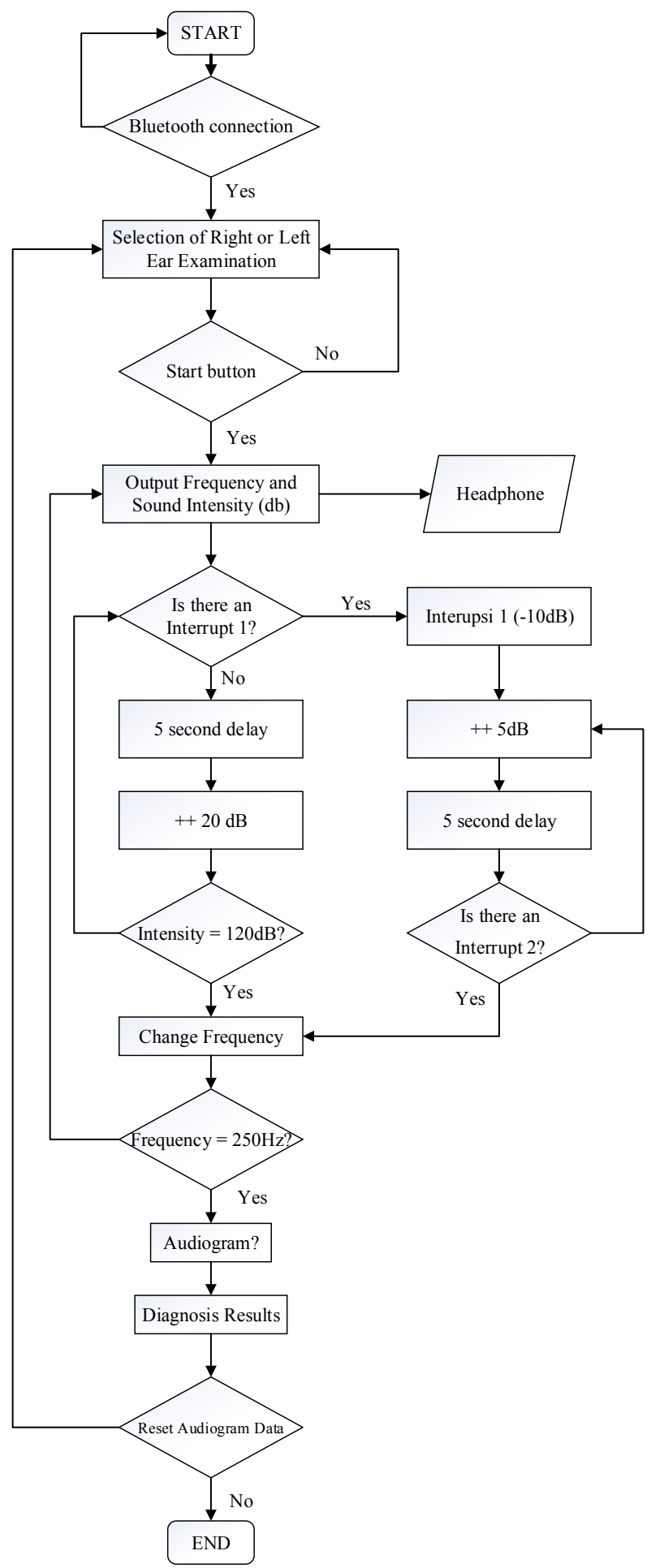

Fig. 2. The Flowchart of Automatic Pure Tone Audiometer

\section{The Flowchart}

The Arduino Program runs like a Flowchart Fig. 2. The Program starts from initializing the Bluetooth connection and choosing a right or left ear examination. If the selection of one has been done. Then press the "Start" button to start the check. The examination starts from the frequency of $1000 \mathrm{~Hz}$ then $2000 \mathrm{~Hz}, 4000 \mathrm{~Hz}, 8000 \mathrm{~Hz}$, $500 \mathrm{~Hz}$ and $250 \mathrm{~Hz}$ sequentially with the initial intensity given $40 \mathrm{~dB}[17],[18]$. If the patient hears sound, the intensity of the voice will be reduced by $10 \mathrm{~dB}$ and if not heard plus $5 \mathrm{~dB}$ [7],[19]. The last intensity results in the patient's hearing will be in the plot of the Audiogram. If the entire frequency check has been completed, press the "diagnose" button on the Audiogram app on Android and the diagnose result will be displayed.

D. circuit

\section{1) frequency Switching}

Intrusion of frequency switching circuit, as shown in Fig. 3, JP1 gets input from Arduino pin. This circuit is a digital switch that serves to select the frequency to be given to the patient. The output pin will be connected to the frequency Pin on the oscillator circuit.

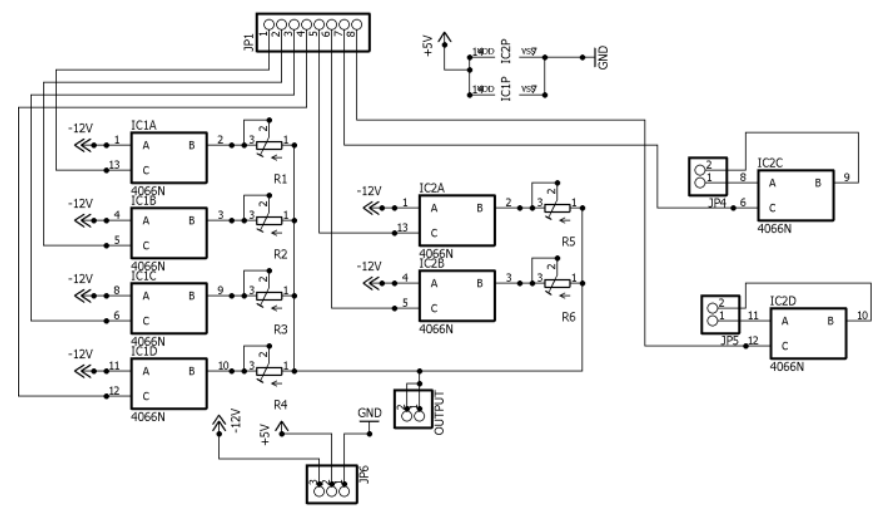

Fig. 3. Frequency Switching with CD4066

2) oscillator

The circuit of the oscillator serves as a sine wave frequency generator, as shown in Fig.4.

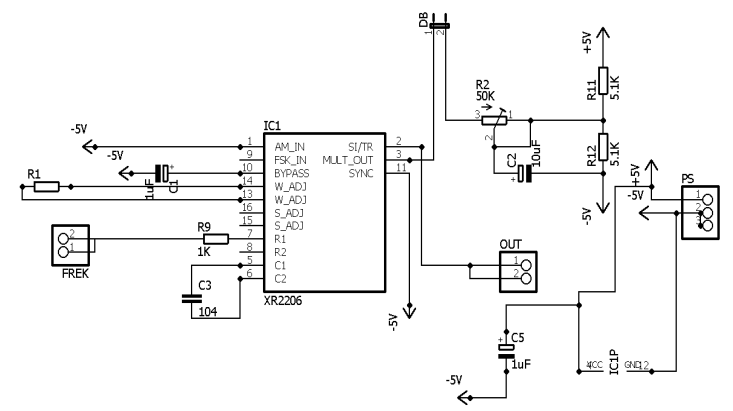

Fig. 4. Generator Frekuensi $250-8000 \mathrm{~Hz}$ with XR2206 
In Fig. 4 The generated frequency of the oscillator range is $250 \mathrm{~Hz}, 500 \mathrm{~Hz}, 1000 \mathrm{~Hz}, 2000 \mathrm{~Hz}, 4000 \mathrm{~Hz}$, and $8000 \mathrm{~Hz}$. The output frequency of the oscillator can be adjusted using the frequency switching circuit, where the output of the circuit is connected to the "FREK" pin.

\section{3) switching Intensity}

Intrusion of frequency switching circuit, as shown in Fig. 5.

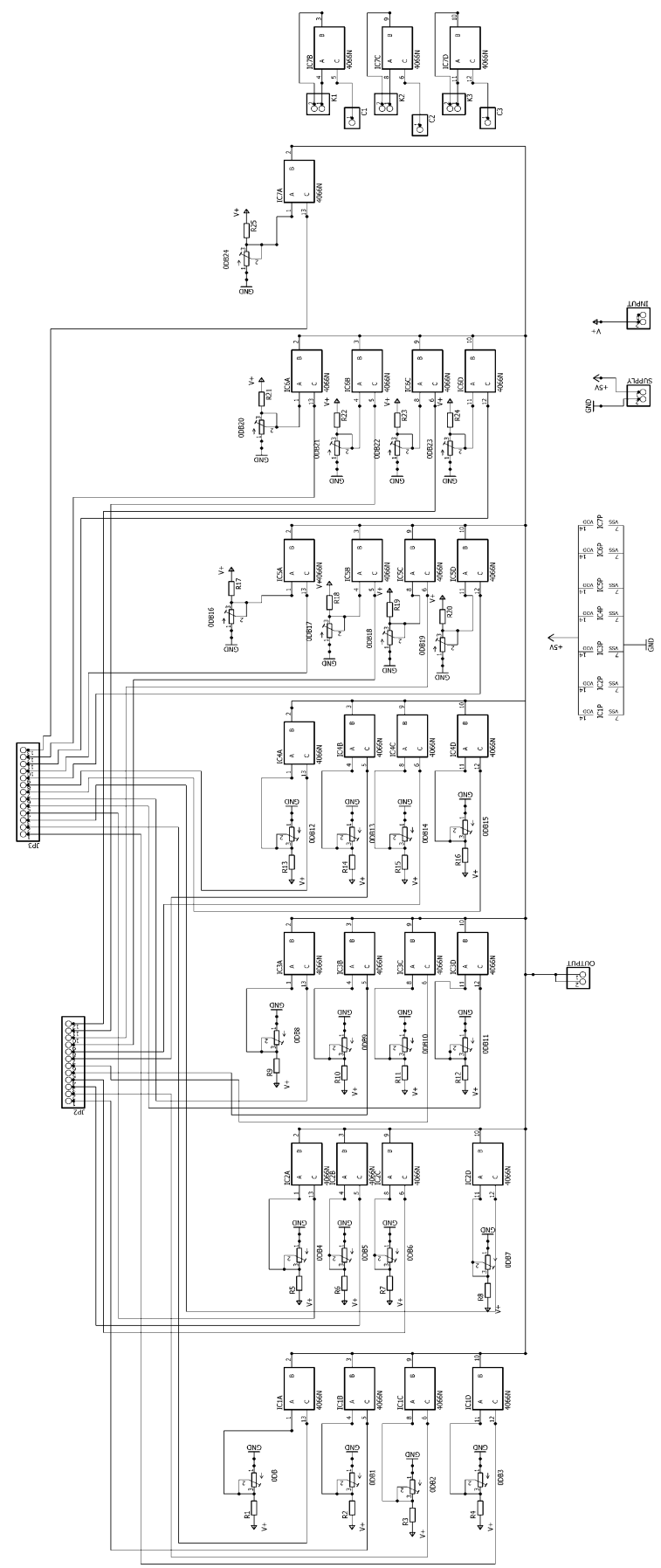

Fig. 5. Switching intensity with CD4066
In Fig. 5 Circuit switching intensity is a circuit of voltage divider to regulate the large amplitude output used for the digital switch intensity is issued. There are 25 resistor variables, to adjust the sound output to produce an intensity from $0-120 \mathrm{~dB}$ with 5 increments. JP2 and JP3 gets input from Arduino pin. This circuit is a digital switch that serves to select the intensity to be given to the patient. The Input pin will be connected to the output Pin on the oscillator circuit. And the output switching circuit intensity will be connected to the amplifier circuit.

\section{4) Amplifier}

The amplifier circuit serves as a reinforcement, as shown in Fig.6.

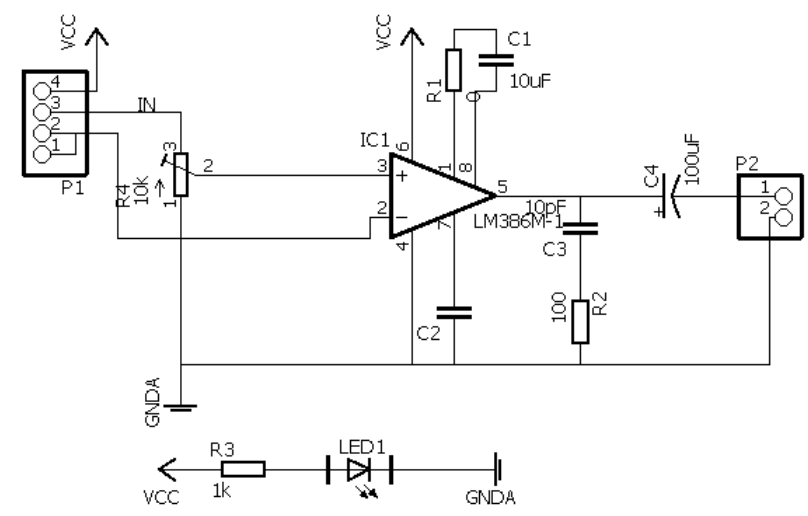

Fig. 6. Amplifier LM386 with gain 200

In Fig. 6 On this circuit the input is taken from the circuit switching intensity to be strengthened. Then the amplifier circuit outputs are connected to circuit breaker and sound connector.

\section{5) Headphone Breaker and pairing circuit}

Intrusion of headphone breaker and pairing circuit, as shown in Fig. 7

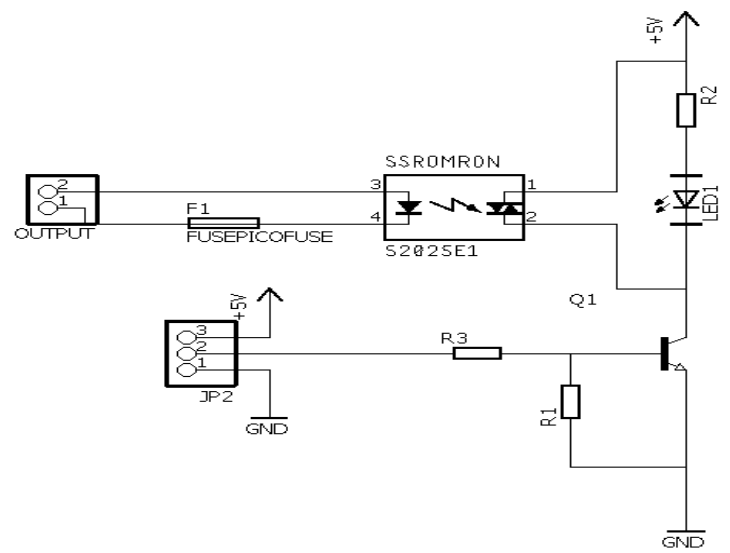

Fig. 7. Headphone Breaker and pairing circuit with Solid State Relay 
In Fig. 7 foot no. 2 pin JP2 Get the input of the Arduino pin. This circuit works for the connecting drivers and voice breakers. The inputs from this circuit are rolled over to the amplifier circuit. And the output is connected to the Right or left Headphone selection circuit.

\section{6) Right or left Headphone selection}

Intrusion of right or left Headphone selection circuit, as shown in Fig. 8, Foot No. 2 pin JP1 and JP2 get the input of the Arduino pin. This circuit serves as the right or left ear check selection driver. Then, its input of circuit breaker and sound connector. The Output of this selection set will be connected to the headphone jack.

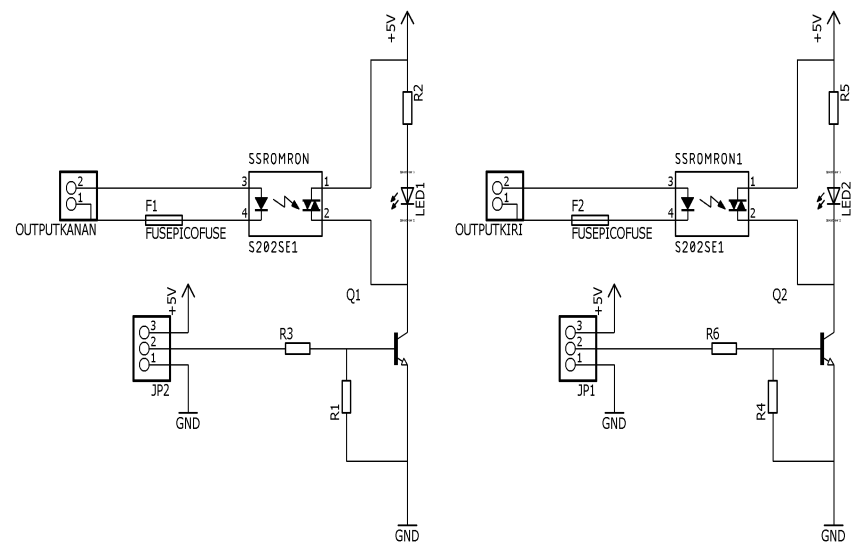

Fig. 8. Right or left Headphone selection circuit with Solid State Relay

\section{7) Pull-up Resistor}

Intrusion of Pull-up resistor circuit, as shown in Fig. 9.

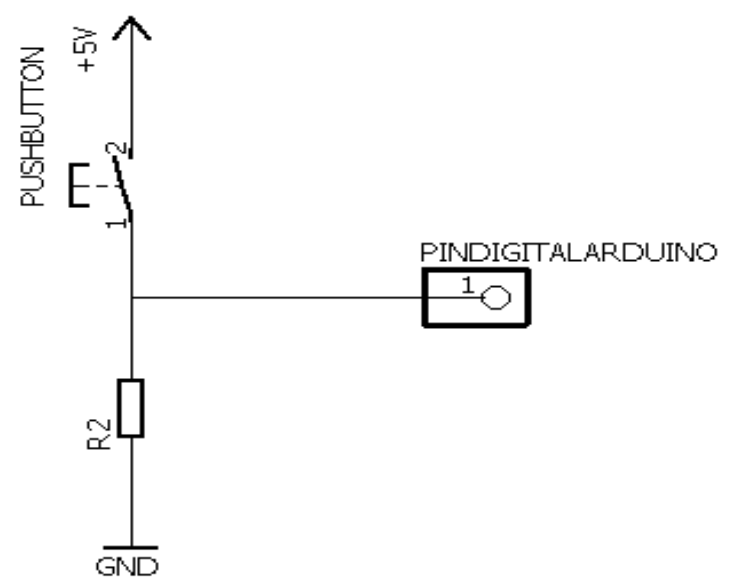

Fig. 9. Pull-up Resistor

In Fig. 9 The pull-up resistor circuit serves to address the floating conditions of the float is a volatile condition between high and low. This circuit is required when providing digital input to the Arduino. The pull-up resistor circuit is used for the left and right ear selection button sets, the Start button and the Interrupt button on an automatic pure tone audiometer.

\section{8) Mikrokontroller circuit}

There is an Arduino Mega Pro mini Module connected to the Bluetooth module HC-05, pull-up resistor, LED indicator as well as the pin of switching frequency and intensity circuit, shown as Fig. 10.

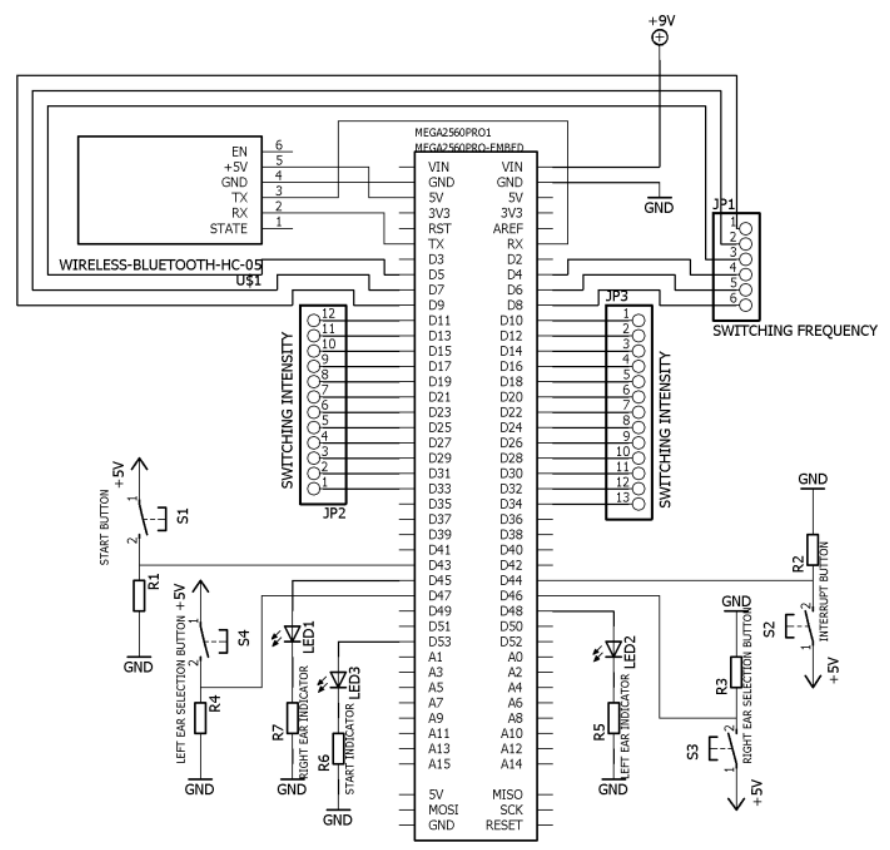

Fig. 10. Mikrokontroller Arduino ATmega2560 Pro Mini circuit

\section{RESULT}

In a study conducted frequency tests on the XR2206 oscillator circuit using the DSO138 Digital Oscilloscope.

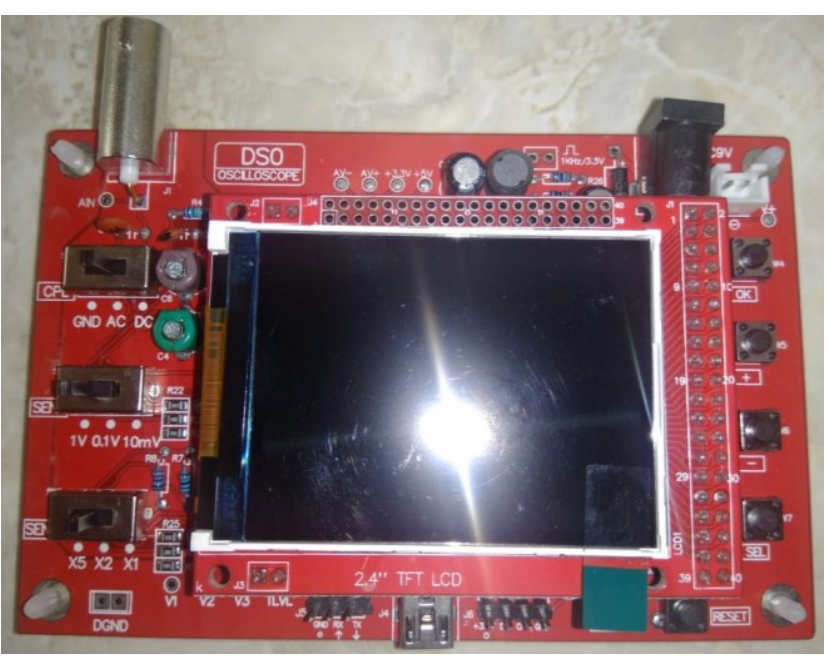

Fig. 11. DSO138 Digital Oscilloscope 
Indonesian Journal of Electronics, Electromedical, and Medical Informatics (IJEEEMI)

Vol. 2, No. 3, Nopember 2020, pp. 113-121

DOI: 10. 35882/ijeeemi.v2i3.2

ISSN: 2656-8624

\section{1) Results of an Automatic Pure Tone Audiometer}

Fig. 12 is the result of an automatic pure tone audiometer from various sides.

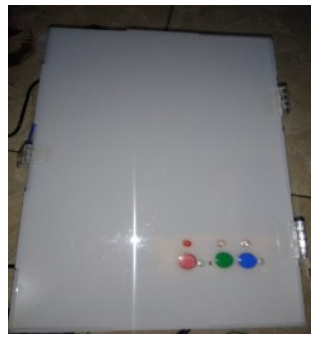

a.

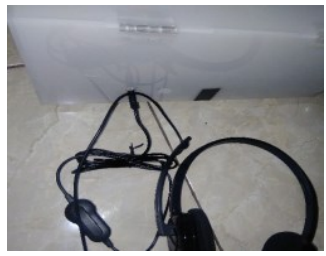

c.

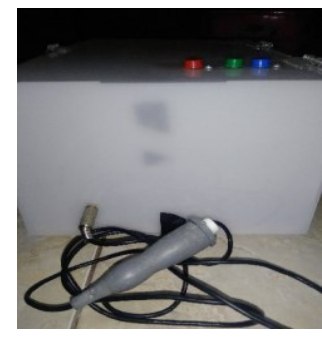

b.

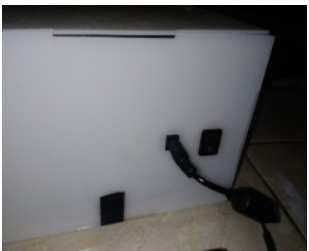

d.
Fig. 12. a. Top view, b. Front view, c. Side view, d.Rear view

In Fig.12a is a hardware image of an auto pure tone audiometer from the top side, there are 3 buttons namely the red button is the Start button, green button is the right ear test selection button, blue button is the left ear test selection button. In Fig. 12b is a hardware image of an auto pure tone audiometer from the front side, there is a patient interrupt button jack. In Fig.12c is a hardware image of an automatic pure tone audiometer from the side, there is a headphone jack and an Arduino program upload. In Fig.12d is an image of an automatic pure tone audiometer from the back side, there is a power switch and a DC jack to connect to the $9 \mathrm{~V}$ adapter.

\section{2) Results of Automatic Pure Tone Audiometer App} Display on Android

Automatic pure tone Audiomter application using Mit App Inventor 2.

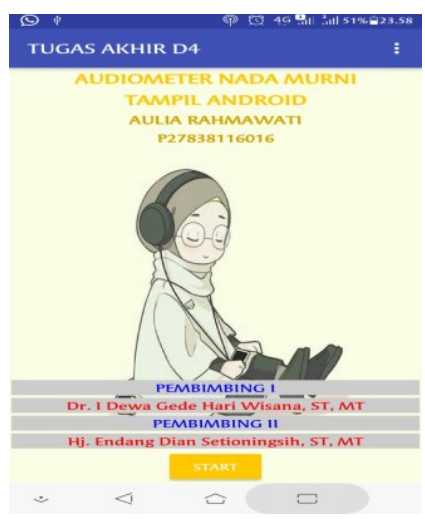

a.

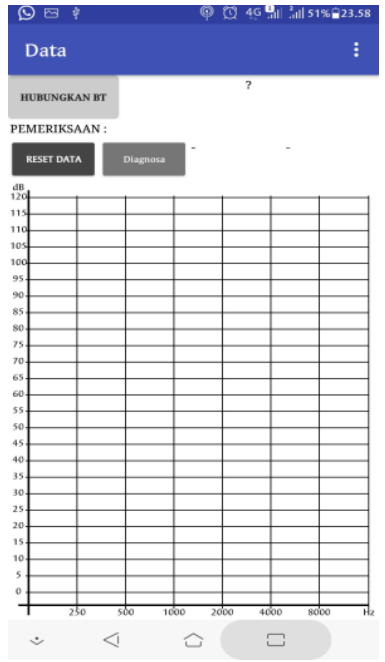

b.

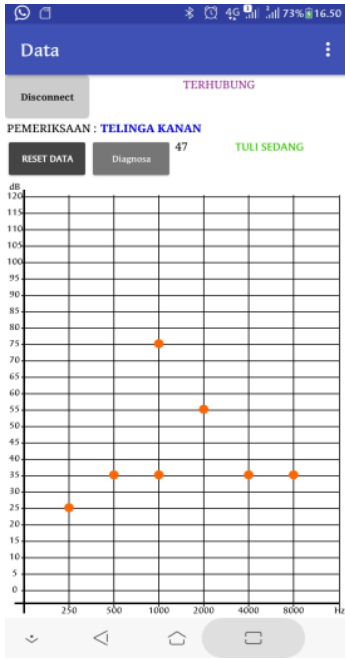

c.
Fig. 13. a.App start view, b. Display before hearing testing, c. Display after hearing test

An auto-pure tone audiometer application is designed using Mit App Inventor 2 to display auditory test results in the form of an audiogram, show in ( Fig.13). In the Fig.13a is the initial view when we open the Audiometer application, there is one Start button to display an Audiogram interface in the Fig.13b. In the Fig. 13b is an audiogram display before the hearing test, there are 3 buttons for connecting Bluetooth, A button to see the patient's diagnose and a button for resetting the data. In the Fig. $13 \mathrm{c}$ is an audiogram display after hearing test, the plot visible to the hearing test results in the $\mathrm{x}$-axis frequency and $\mathrm{y}$ axis of sound intensity. If the hearing test of the entire frequency has been completed can be seen the results diagnose the patient by pressing the diagnose button.

According to the International Classification of Hearing loss, to calculate the rate of the hearing threshold by summarizing 4 values namely the lowest sound intensity audible at frequencies 500, 1000, 2000 and $4000 \mathrm{~Hz}$, and then divided the number of frequencies calculated i.e. 4 to get the average arithmetic using the following formula[20]:

$$
I=\frac{I(500)+I(1000)+I(2000)+I(4000)}{4}
$$

This frequency option is based on the fact that it is a frequency when speaking [20]. According to the calculated average value, the level of hearing loss is determined according to the International Organization for Standardization as shown in Table 1 
TABLE I. HEARING IMPAIRMENT RATE

\begin{tabular}{cc}
\hline Hearing impairment rate & $\begin{array}{r}\text { Range of Hearing } \\
\text { disorders (dB HL) }\end{array}$ \\
\hline Normal & -10 to 25 \\
Mild deafness & 26 to 40 \\
Moderate deafness & 41 to 60 \\
Severe deafness & 61 to 90 \\
Very heavy deafness & $\geq 91$ \\
\hline
\end{tabular}

\section{3) Results of Frequency Measurement on Oscillator Circuit}

The resulting frequency of the oscillator circuit can be set at the frequency switching circuit resistor variable. This frequency measurement is performed 6 times the measurement with the result as shown in Table II.

TABLE II. FREQUENCY MEASUREMENT RESULTS

\begin{tabular}{ccc}
\hline $\begin{array}{c}\text { Frequency Setting } \\
(\mathrm{Hz})\end{array}$ & Error (\%) & Standard deviation \\
\hline 250 & 0.05 & 0.136930639 \\
500 & 0.87 & 0.52569294 \\
1000 & 3.95 & 1.378404875 \\
2000 & 1.23 & 3.265986324 \\
4000 & 1.68 & 4.676180778 \\
8000 & 0.40 & 4.131182236 \\
\hline
\end{tabular}

Based on Tabel II, shows the result of measuring frequency value with 6 measurements using the DSO138 Digital Oscilloscope obtained different results or the difference in the value of measurement with the desired value, causing the presence of the most error value of $3.95 \%$ at $1000 \mathrm{~Hz}$ frequency. The difference in measurement results resulting in the error of each frequency varies due to the frequency setting using a resistor variable that has different tolerance and precision values in each variable resistor each frequency.

\section{4) Results Automatic Pure Tone Audiometer Program Arduino}

In the journal Arduino program divided by 3, which is the choice program of ear hearing test right or left, the program control automatic pure tone Audiometer and Send the last frequency and intensity data in hearing the patient to Mit App Inventor 2.

Listing program 1 . The program is to choice of ear hearing test right or left.

void $\operatorname{loop}()$ \{

int kanan= digitalRead(tombolkanan);

int kiri= digitalRead(tombolkiri);

int mulai= digitalRead(tombolmulai);

int interupsi $1=$ digitalRead(tombolinterupsi1);

menu00 :

while (1)

Serial.println ("Pilih Telinga Yang Diperiksa");

delay (1000);

int kanan= digitalRead(tombolkanan);

int kiri= digitalRead(tombolkiri);

digitalWrite (IndikatorMulai,HIGH);

digitalWrite (pilihKanan, LOW);

digitalWrite (pilihKiri, LOW);

digitalWrite(35,LOW);

if $($ kanan $==\mathrm{HIGH})\{$

delay (1000);

goto menu01; \}// Choosing a right ear hearing test

else if $($ kiri $==\mathrm{HIGH})\{$

delay (1000);

goto menu02; $\}$ \}// Choosing a left ear hearing test

Listing program 2. The program is to control automatic pure tone Audiometer

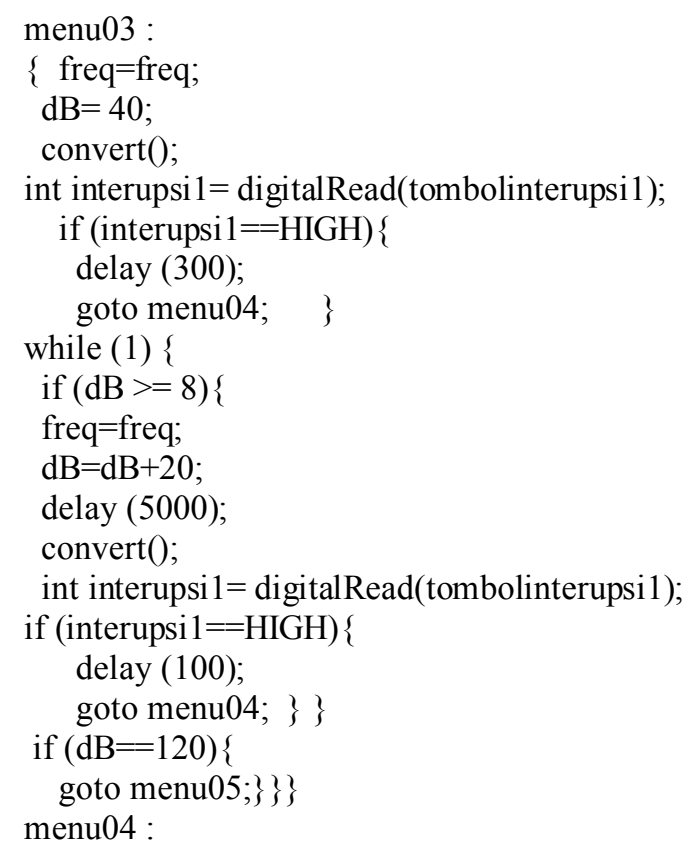




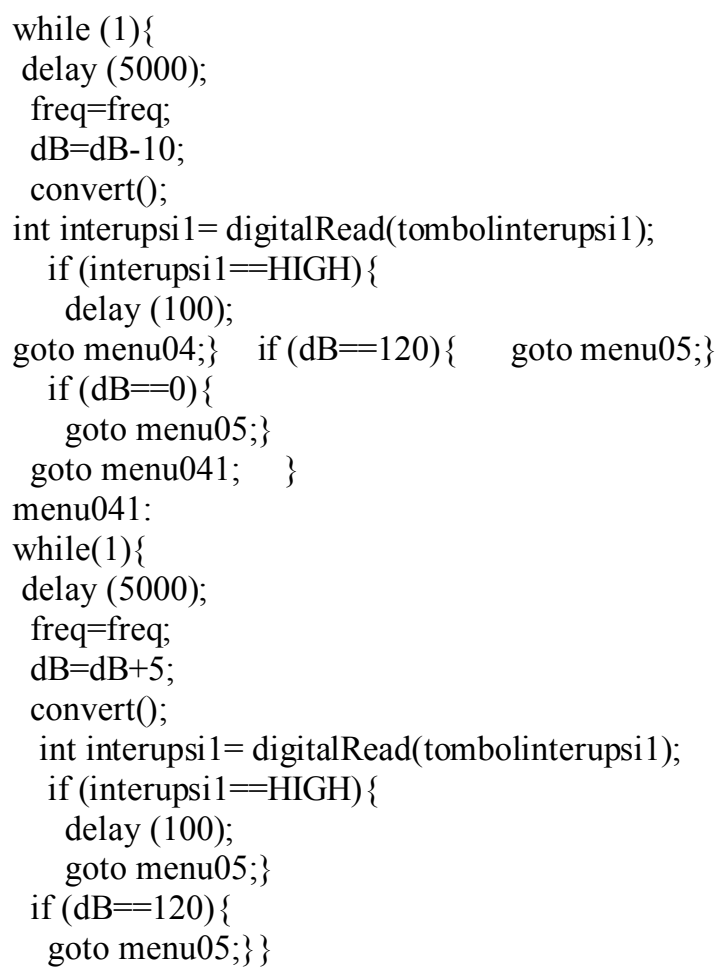

Listing program 3. The program is to Send the last frequency and intensity data in hearing the patient to Mit App Inventor 2

Serial.println ("A" + String(freq));//Sending frequency data

Serial.println ("B" + String $(\mathrm{dB}))$;// Sending intensity data

6) The results of Automatic Pure Tone Audiometer Program Mit App Inventor 2

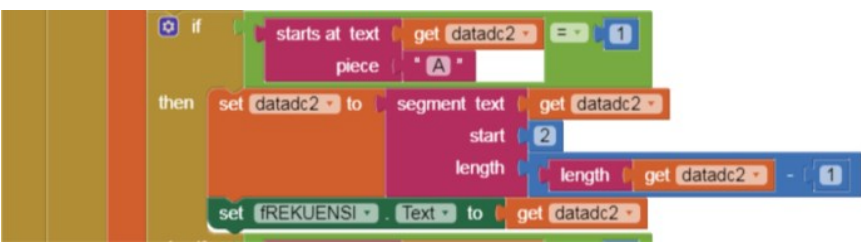

Fig. 14. The Mit App Inventor 2 Program when receiving A record is initialized as a frequency data

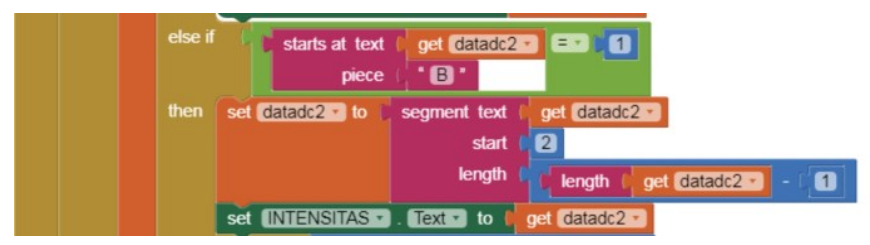

Fig. 15. The Mit App Inventor 2 Program when receiving B record is initialized as a intensity data

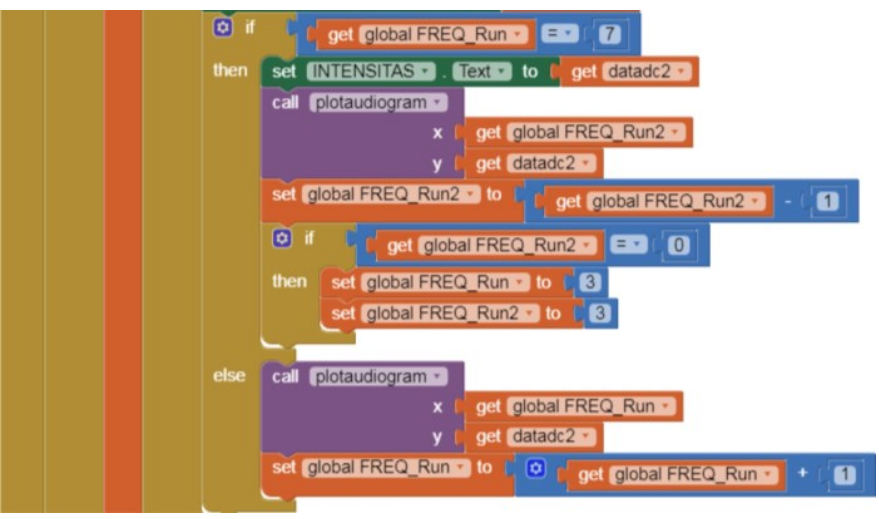

Fig. 16. The Mit App Inventor 2 Program when performing data ploting

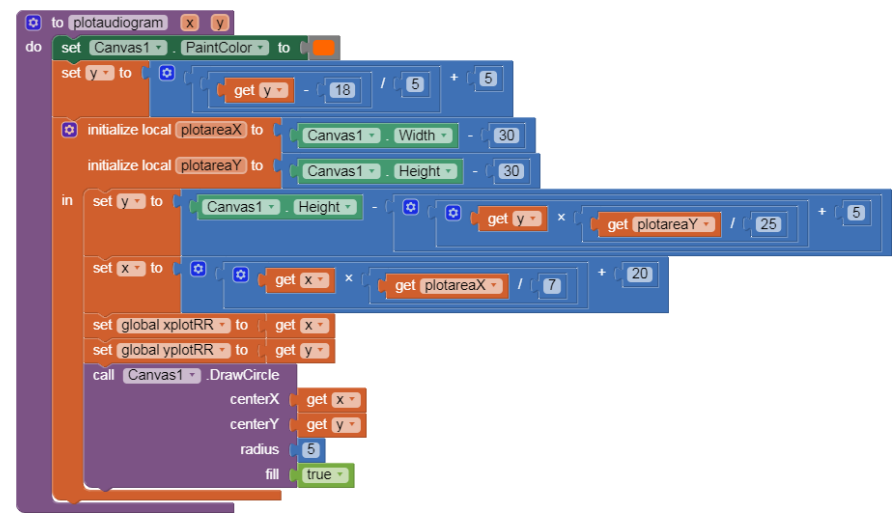

The Mit App Inventor 2 Program when creating a circular plot on an audiogram chart

\section{Discussion}

Based on the frequency measurement using the DSO138 Digital Oscilloscope as a 6-time measurement. TABLE II shows that using the CD4066 frequency switching circuit and the XR2206 oscillator range are the differences in measurement results that result in each frequency being errorvarying due to frequency setting using resistor variables that have different tolerance and precision values in each resistor variable at each frequency. This auto pure tone audiometer can display audiograms and results diagnose hearing testing. This is a significant improvement, since to date, the pure tone audiometer does not display the results diagnose the hearing test.

Isler's pure tone audiometer has 3 auditory test modes: Manual mode, automatic mode, and voice control mode. The Audiometer is also equipped with an audiogram on a TFT display of 4.3 "and uses the STM32F746 microcontroller[13]. The study has only 1 auditory test mode, which is an automatic mode with an audiogram display on an Android smartphone. However, the study has been supplemented by hearing tests. 
In a practical system, an automatic pure tone audiometer with Audiogram display and results diagnose hearing testing can improve hearing loss testing service in the clinic/hospital, can save time for hearing loss testing and can facilitate audiologist when conducting hearing tests. Despite an improved audiometer system, this study does not measure output intensity generated.

\section{Conclusion}

A pure tone audiometer with an automatic mode using Arduino microcontrollers for efficiency time for hearing loss testing and facilitating audiologist during hearing testing. This study has found that the Mit App Inventor 2 platform can be used to create an Audiogram application that can be used on an Android Smartphone, a combination of the XR2206 oscillator series, a circuit of frequency Switching and intensity can be used for automatic testing modes. In short, the study introduces the following auto pure tone Audiometer with Audiogram display and results diagnose hearing testing on Android smartphones. Further experimental investigation is needed to estimate the accuracy and precision of the variable resistors used, replacing the amplifier circuit to achieve maximum intensity.

\section{REFERENCE}

[1] M. Wereski, "The Threshold of Hearing," STEAM J., vol. 2, no. 1, pp. 1-4, 2015, doi: 10.5642/steam.20150201.20.

[2] B. Kim and M. Bae, "A Study on the Self Partial Hearing Test for Voice Sub-band," Int. J. Eng. Res. Technol., vol. 12, no. 11, pp. 1929-1934, 2019.

[3] World Health Organization (WHO), "Deafness and hearing loss," World Health Organization (WHO), $2019 . \quad$ https://www.who.int/news-room/factsheets/detail/deafness-and-hearing-loss (accessed Aug. 08, 2019).

[4] R. Rani, "Portable Audiometer for Detecting Hearing Disorder at an Early Stage for Cancer Patient," in International Conference on Automatic Control and Dynamic Optimization Techniques (ICACDOT), 2016, pp. 119-123.

[5] American Speech-Language-Hearing Association, "Type, Degree, and Configuration of Hearing Loss," American Speech-Language-Hearing Association (ASHA). 2015.

[6] W. Ren et al., "Preliminary application of intraoperative hearing monitoring by tone pip ABR via loudspeakers," vol. 6489, no. May, 2017, doi: 10.1080/00016489.2016.1218049.

[7] F. Chen, S. Wang, J. Li, H. Tan, W. Jia, and Z. Wang, "Smartphone-Based Hearing Self-Assessment System using Hearing Aids with Fast Audiometry Method," IEEE Trans. Biomed. Circuits Syst., vol. PP, no. c, p.
1, 2018, doi: 10.1109/TBCAS.2018.2878341.

[8] S. A. Ophir, H. Lior, and M. Himmelfarb, "Smartphone-based audiometric test for screening hearing loss in the elderly," 2015, doi: 10.1007/s00405-015-3533-9.

[9] H. Y. Lin et al., "Assessment of hearing loss by puretone audiometry in patients with mucopolysaccharidoses," Mol. Genet. Metab., vol. 111, no. 4, pp. 533-538, 2014, doi: 10.1016/j.ymgme.2014.02.003.

[10] R. R. Medumand and C. P. Product, "Hearing Test Method and System, Readable Record Medium and Computer Program Product," 2016.

[11] S. Tan, S. Loh, and W. Chee, "Speech-Enabled Pure Tone Audiometer," in International Symposium on Intelligent Signal Processing and Communication Systems, 2007.

[12] Y. İşler, Y. Ö. Uzun, and B. M. Bölümü, "Mikrodenetleyici Tabanlı Odyometri Cihazı Tasarımı Microcontroller-Based Audiometer Device Design," pp. 659-663, 2012.

[13] Y. and Y. Ö. U. İşler, “Audiometer Device Design with Integration to Different Sources," IEEE, 2016, doi:

https://doi.org/10.1109/TIPTEKNO.2016.7863064.

[14] I. Ahn, "A Study on a Automatic Audiometry Aid by PSM," Int. J. Eng. Res. Technol., vol. 11, no. 8, pp. 1263-1272, 2018.

[15] M. Gargouri, M. Chaoui, and A. Kachouri, "Conception of a Software Pure Tone Audiometer Application," 2018 15th Int. Multi-Conference Syst. Signals Devices, pp. 619-622, 2018.

[16] S. M. Govender and M. Mars, "International Journal of Pediatric Otorhinolaryngology Validity of automated threshold audiometry in school aged children," Int. J. Pediatr. Otorhinolaryngol., vol. 105, no. December 2017, pp. 97-102, 2018, doi: 10.1016/j.ijporl.2017.12.008.

[17] L. W. \& Wilkins, Special function tests. 2020.

[18] J. Graley, D. Meinke, T. Madison, and T. Audiometry, Guidelines for Manual Pure-Tone Threshold Audiometry. America: American Speech-LanguageHearing Association, 2005.

[19] W. Leung, J. Jia, Y. Wu, J. Long, and L. Cai, “THear : Development of a Mobile Multimodal Audiometry Application on a Cross-Platform Framework," IEEE J. Transl. Eng. Heal. Med., pp. 0-4, 2016.

[20] K. Khatter, "Personal music players and hearing loss: Are we deaf to the risks?," vol. 5, no. 3, pp. 137-138, 2011. 